\title{
Een ander perspectief op het spreidingsbeleid voor statushouders
}

\author{
Emily Miltenburg ${ }^{*}$
}

In zijn afscheidsrede stelt Sako Musterd de vraag of segregatie wel altijd vormen aanneemt die ingrijpende mengingspraktijken legitimeren. Moet er niet meer ruimte zijn voor de woonvoorkeuren van huishoudens? Een groep waarbij deze voorkeuren zelden worden meegewogen, zijn vluchtelingen met een verblijfsvergunning (statushouders). Wie bepaalt waar zij komen te wonen en wat kunnen hiervan de gevolgen zijn? Dit artikel biedt een inkijk in de aannames bij - en ontwikkelingen in - het huisvestingsbeleid van statushouders.

\section{De vlucht en de landing}

Een vluchteling verlaat huis en haard niet vrijwillig, maar is gevlucht voor vervolging, geweld of oorlog. Bij aankomst in Nederland moet een vluchteling zich eerst melden en registreren bij de Immigratie- en Naturalisatiedienst (IND) in Ter Apel. $\mathrm{Na}$ de asielaanvraag verhuist de vluchteling naar een asielzoekerscentrum (azc) in afwachting van de beslissing om in Nederland te mogen blijven (Rijksoverheid, 2017). Het Centraal Orgaan Opvang Asielzoekers (COA) is verantwoordelijk voor de toewijzing aan een azc. Als een vluchteling een verblijfsvergunning krijgt (en daarmee een status, daarom spreekt men van statushouders), komt diegene in aanmerking voor een huurwoning. Gemeenten hebben de plicht een vastgesteld aantal statushouders te huisvesten. Deze jaarlijkse taakstelling, opgelegd door het ministerie van Binnenlandse Zaken, is afhankelijk van het aantal inwoners in een gemeente. Dit is onderdeel van een spreidingsbeleid waarbij statushouders evenredig over verschillende gemeenten in het land worden gespreid. De achterliggende aanname van dit beleid is dat deze spreiding de integratie van statushouders ten goede komt en dat door de gelijkmatige verdeling het draagvlak onder de Nederlandse bevolking behouden blijft (Jansen, 2006; Van Liempt \& Staring, 2020).

\section{Locatie, locatie, locatie}

Door het spreidingsbeleid hebben statushouders over het algemeen vrijwel geen zeggenschap over waar ze gehuisvest worden. Het COA bepaalt waar ze gaan wonen, maar kan hier waar mogelijk wel rekening houden met een studie, baan, eerstegraads familieleden of medische omstandigheden. ${ }^{1}$ Ondanks de mogelijkheid om deze uitzonderingen te maken, lijkt plaatsing in de praktijk toch op willekeur te berusten en wordt er in eerste instantie een behoorlijk evenredige sprei-

* Dr. Emily Miltenburg is onderzoeker bij het Sociaal en Cultureel Planbureau. 
ding over het land gerealiseerd (zie bijvoorbeeld de kaart met de gemeente van vestiging van recent gehuisveste Syriërs: Huisman, 2020). Op het moment dat een statushouder een woning in een gemeente krijgt aangeboden, moet diegene de woning in principe accepteren.

Gemeenten dragen vervolgens de verantwoordelijkheid om statushouders wegwijs te maken in hun gemeente en het participatieverklaringstraject aan te bieden (een verplichte kennismaking met de rechten, plichten en waarden van de Nederlandse samenleving). Hierbij hebben gemeenten een zekere mate van vrijheid; de begeleiding van statushouders kan dus van gemeente tot gemeente flink verschillen. $^{2}$

Op den duur kunnen statushouders wel verhuizen naar een andere gemeente. Van de meest recente groep vluchtelingen uit Syrië verhuisden nog maar weinig mensen. Maar zij die verhuizen, hebben een voorkeur voor meer stedelijke gebieden (Boot \& Driessen, 2019). ${ }^{3}$ Eerder onderzoek naar statushouders die tussen 1995 en 2005 werden uitgeplaatst, laat zien dat de helft van de statushouders nog steeds in de regio woont waar ze zijn uitgeplaatst. De andere helft vertrekt naar een andere regio of het buitenland. Het vertrek ligt hoger in dunbevolkte gebieden, en grote steden - zoals Rotterdam en Den Haag - zijn juist in trek als bestemming. Een mogelijke reden voor verhuizing naar deze gebieden is de beschikbaarheid van werk of een opleiding, maar ook de aanwezigheid van mensen uit hetzelfde herkomstland kan een reden zijn om te verhuizen (Gerritsen, Kattenberg \& Vermeulen, 2018).

\section{De voor- en nadelen van een enclave}

Veel woonbeleid wordt nu juist vormgegeven op basis van de aanname dat aan wonen in een 'etnische enclave' (een woonwijk met een concentratie van mensen met dezelfde herkomst en een gedeelde culturele identiteit) verschillende negatieve gevolgen kleven. Zo zou deze ruimtelijke segregatie het bemoeilijken om sociale contacten aan te gaan met mensen buiten de eigen herkomstgroep en zorgen voor een afstand tot de samenleving (Uslaner, 2012; Van der Laan-BoumaDoff, 2007). Het wonen in deze gesegregeerde gebieden zou daarnaast de maatschappelijke kansen belemmeren en weinig uitzicht geven op het verbeteren van de arbeidsmarktpositie.

Toch worden er ook positieve kanten benoemd van de nabijheid van mensen uit hetzelfde herkomstland: deze concentratiewijken zouden juist bevorderend voor integratie kunnen zijn omdat migranten in deze buurten meer waardevolle contacten hebben, zowel voor emotionele steun als voor informatie over werk waarmee ze hun positie op de arbeidsmarkt kunnen verbeteren (Andersson \& Hammarstedt, 2015; Edin, Fredriksson \& Åslund, 2003; Musterd, 2003; Zhou \& Portes, 1992), zeker voor mensen die nog maar kort in het land zijn (Ager \& Strang, 2008).

Een voorkeur om in de nabijheid van herkomstgenoten te wonen en de voordelen daarvan voor arbeidsmarktkansen komen ook naar voren bij statushouders. Zo zijn er aanwijzingen dat een kleine groep recent aangekomen Syriërs bovengemid- 
deld vaak naar Twente trekt vanwege ondersteuning door de aanwezige Syrischorthodoxe gemeenschap (Van Liempt \& Staring, 2020; Boot \& Driessen, 2019). Uit eerder onderzoek naar statushouders die eind jaren negentig uit voormalig Joegoslavië naar Nederland kwamen, blijkt dat zij relatief vaak een baan vinden in Limburg, Rotterdam en Amsterdam, regio's waar ook al relatief veel mensen uit dit herkomstland woonden (Gerritsen e.a., 2018, 10).

Er zijn inmiddels veel systematische studies uitgevoerd die gebruikmaken van het 'natuurlijke experiment' waarbij statushouders willekeurig en evenredig over gemeenten worden verdeeld. Uit dat Amerikaanse en Europese onderzoek blijkt niet zozeer dat het wonen in 'etnische enclaves' met veel mensen met dezelfde herkomst bevorderlijk is (bijvoorbeeld Beaman, 2012; Damm, 2009; Edin e.a., 2003; Martén, Hainmueller \& Hangartner, 2019), maar dat vooral de sociaaleconomische kenmerken (bijvoorbeeld de arbeidsparticipatie) van deze herkomstgenoten de arbeidsmarktparticipatie bevorderen. De kans op arbeidsparticipatie neemt dus toe als er in de buurt waar de migrant zich vestigt al een gevestigde migrantengemeenschap (herkomstgenoten met een baan) aanwezig is (Pinkster, 2009). De samenstelling van de eerste buurt waar een statushouder terechtkomt lijkt bepalend te zijn voor de arbeidskansen van statushouders (Andersson, Musterd \& Galster, 2019) en voor de uitstroom uit een uitkering naar een baan (Kristiansen, 2020). Een willekeurig spreidingsbeleid waarbij helemaal geen rekening wordt gehouden met werk- en opleidingsmogelijkheden van de statushouders kan juist zeer nadelig zijn voor hun arbeidsmarktintegratie (Fasani, Frattini \& Minale, 2018). Deze bevindingen wringen met het vaak gedeelde argument dat een willekeurig spreidingsbeleid bevorderend is voor de integratie.

Veel beleidsmakers zagen een ongelijke spreiding van nieuwkomers en gevestigden namelijk als ongewenst omdat het sociale mobiliteit in de weg zou staan. Toch gaan er steeds meer stemmen op dat het spreidingsbeleid de integratie van een nieuwkomer ook lastiger kan maken (zie Huizinga, 2019). Ook de statushouder zelf merkt dat de regio van uitplaatsing uitmaakt voor de geboden kansen. Uit Nederland Papierenland (een SCP-publicatie over de ervaringen van Syrische statushouders met participatiebeleid) blijkt dat statushouders, hoewel ze in eerste instantie vooral blij zijn met het moment een eigen woning te kunnen betreden, beseffen dat hun nieuwe woonplaats in sterke mate de mogelijkheden lijkt te bepalen om aan hun toekomst in Nederland te kunnen werken (Van Liempt \& Staring, 2020).

Omdat er bij de toewijzing van statushouders aan gemeenten meestal geen rekening wordt gehouden met de voorkeuren, levensfase en kennis en vaardigheden van de statushouder, leidt dat soms tot frustratie bij statushouders en zelfs tot een gevoel van achterstelling als hen via kennissen ter ore komt wat de mogelijkheden in een andere gemeente zijn. De huisvesting is meer dan een woonplaats, het is het begin van het integratietraject in de Nederlandse samenleving, het bepaalt de arbeidsmarktkansen en mogelijkheden voor een opleiding en het opbouwen van een sociaal leven (Van Liempt \& Staring, 2020). Uit deze ervaringen klinkt door dat meer doordenking van de koppeling van statushouders aan regio's gewenst is. Statushouders worden nog te veel over Nederland verdeeld 
zonder bijvoorbeeld rekening te houden met de mate waarin er voor hen in de regio wel of geen werk beschikbaar is (Engbersen e.a., 2015).

\section{Screening en matching}

De laatste jaren is er dan ook meer aandacht voor de kansrijke koppeling aan de gemeente waar een statushouder komt te wonen. Door bij toewijzing aan gemeenten meer rekening te houden met het profiel van de statushouder zou de aansluiting op de beschikbare opleidingsmogelijkheden en arbeidsmarktkansen meer optimaal kunnen zijn (COA, 2020). Er zijn pilots vanuit het COA voor 'screening en matching' van statushouders op basis van hun arbeidsverleden en opleidingsachtergrond. Het streven is om de statushouder ook te plaatsen in een azc in de omgeving van deze 'kansrijke koppelgemeente'. Maar omdat de opvangcapaciteit niet evenredig over Nederland verdeeld is en de taakstelling is dat vergunninghouders evenredig aan gemeenten toegewezen worden, is dat niet altijd mogelijk (VNG, 2016).

\section{Niet de statushouder of het COA, maar een algoritme bepaalt?}

Om de match tussen de statushouder en de regio te verbeteren lijkt het zinvol om de kenmerken van beide in beschouwing te nemen. Er zijn inmiddels ook plannen om een algoritme voor het COA te laten berekenen waar statushouders het best geplaatst kunnen worden om beter aan te sluiten bij de lokale arbeidsmarkt en opleidingsmogelijkheden (Willen, 2019). Een experiment met deze big-datatechniek in de Verenigde Staten en Zwitserland toonde dat het aantal statushouders dat een baan vond flink steeg en dat het vinden van een baan ook sneller ging (Bansak e.a., 2018). Een verkenning van het Centraal Planbureau (CPB) geeft aan dat het gebruik van een dergelijk algoritme ook voor statushouders in Nederland veelbelovend kan zijn (Gerritsen e.a., 2018). ${ }^{4}$ Maar de baankansen zijn in plattelandsgemeenten over het algemeen minder. Door met algoritmes betere koppelingen te maken naar baankansen worden er minder mensen door het COA toegewezen aan bepaalde kleinere gemeenten, waardoor de huisvestingsopdracht daar niet wordt gehaald (Sinnema, 2020). De doelen achter het toewijzingsalgoritme en de gemeentelijke taakstelling kunnen elkaar dus bijten.

Daarnaast speelt er meer dan de aanwezigheid van (geschikte) banen: ook de bereikbaarheid van taalscholen (in minder stedelijke gebieden is er veel reistijd naar taalscholen), de huishoudenssamenstelling (jonge alleenstaanden wonen liever in de stad dan gezinnen), de beschikbaarheid van specifieke onderwijsinstellingen (voor specifieke opleidingen die niet in elke regio beschikbaar zijn) en verschillen in gemeentelijk beleid (zoals de mogelijkheden om na je dertigste nog te mogen studeren met behoud van uitkering) kunnen tussen statushouders tot verschillende voorkeuren in woongemeenten leiden (Van Liempt \& Staring, 2020). Deze veelvoud aan voorkeuren maakt een algoritme al snel ingewikkeld. 


\section{Conclusie}

Over het algemeen zijn Nederlanders vrij om te gaan en staan waar ze willen. Deze individuele woonvoorkeuren, maar ook de mogelijkheden die mensen hebben, leiden tot segregatie. Bij bewoners van sociale huurwoningen proberen de overheid en woningcorporaties hier op in te grijpen door in te zetten op menging. Bij statushouders specifiek is het spreidingsbeleid nog dominant, waarbij er nagenoeg geen ruimte is voor individuele voorkeuren. Zelfs als er al rekening wordt gehouden met het profiel van de statushouder, wordt de matching alsnog door een ambtenaar (of in de toekomst mogelijk door een algoritme) gedaan. Bovendien staan deze pogingen tot matching nog in de kinderschoenen en lijkt de uitplaatsing vaak nog op willekeur te berusten (Huizinga, 2019).

De vraag is of het voorkomen van deze segregatie en het uitsluiten van individuele voorkeuren tot de beste integratiekansen leidt. We weten van gevestigde vluchtelingengroepen dat een aanzienlijk deel over de jaren heen alsnog vanuit dunbevolkte gebieden naar steden verhuist. Door vooraf bij uitplaatsing al meer rekening te houden met de regionale arbeidsmarkt en andere individuele voorkeuren kan dat aantal verhuizingen mogelijk beperkt worden. Het kan dus beter zijn om een meer ontspannen perspectief op uitplaatsing van statushouders te hanteren, waarbij het evenredige spreidingsbeleid deels wordt losgelaten. Toch zal dat afbouwen van de evenredige verdeelsleutel over Nederland niet zomaar gaan: het draagvlak voor het opnemen van statushouders kan afnemen als bepaalde gebieden het idee hebben onevenredig veel statushouders te moeten huisvesten; een evenredige verdeling wordt namelijk over het algemeen als meer eerlijk gezien (Bansak, Hainmueller\& Hangartner, 2017; Gerritsen e.a., 2018).

Een gulden middenweg tussen een volledig willekeurig spreidingsbeleid en een beleid dat huisvesting volledig vrijlaat zal waarschijnlijk leiden tot betere kansen voor statushouders op werk en op het thuis voelen in de nieuwe omgeving. Er zijn steeds meer aanwijzingen dat willekeurige spreiding op termijn niet goed is voor de sociaaleconomische kansen van een statushouder. Hierbij moet ook aandacht zijn voor het draagvlak in de bevolking, evenals voor een zorgvuldige afstemming van woonvoorkeuren, ambities en kenmerken van de statushouders. Een goede match bij de eerste huisvesting is dus cruciaal, omdat de statushouder dan waarschijnlijk honkvaster is, en veel verhuizingen in de eerste jaren kunnen het verplichte inburgeringsproces alleen maar verstoren. Door de nieuwe Wet inburgering, waar de gemeente een belangrijke regierol krijgt (intake, persoonlijk plan inburgering en participatie) om de statushouders zo snel mogelijk te laten meedoen in de Nederlandse samenleving, is het extra belangrijk om de koppeling van statushouders aan gemeenten bedachtzaam te doen.

\section{Noten}

1 De vluchteling moet dit aantonen door bijvoorbeeld een arbeidscontract, een doktersverklaring of de inschrijving bij een studie. Op basis van deze factoren wordt een 
bepaalde gemeente gezocht om de huisvesting te verzorgen. Zie www.vluchtelingenwerk.nl/feiten-cijfers/procedures-wetten-beleid/huisvesting.

2 In 2022 treedt de nieuwe Wet inburgering in werking. Gemeenten krijgen vanaf dan de regie over de uitvoering van de inburgering van nieuwkomers, met als taken onder andere de intake met de inburgeraar, het opstellen van een persoonlijk plan inburgering en participatie (PIP), het inburgeringsaanbod waarborgen en de voortgang monitoren, het maatschappelijk begeleiden en de financiële ontzorging van bijstandsgerechtigde statushouders.

3 Door de burgeroorlog in Syrië hebben velen het land gedwongen moeten verlaten en een deel heeft hun toevlucht gezocht in de Europese landen. De periode van grote instroom begon in 2014, met een piek in het najaar van 2015. In Nederland wonen momenteel ongeveer 100.000 Syriërs en ze vormen nog steeds de grootste groep vluchtelingen in de opvang.

4 Bij het data-gedreven toewijzingsalgoritme voor de verdeling van statushouders wordt het model eerst getraind op basis van arbeidsmarktprestaties van statushouders die eerder zijn uitgeplaatst (zie het oorspronkelijke artikel van Bansak e.a., 2018 en de uitleg van Gerritsen e.a., 2018). De baankans van een statushouder is bepaald op basis van geslacht, leeftijd, herkomstland en opleidingsniveau. Hierdoor kan voor elke statushouder een inschatting gemaakt worden van wat de kans in de regio is om daar aan het werk te kunnen. Vervolgens wordt bij toewijzing de stap genomen van individuele statushouders naar huishoudens om de gemiddelde baankans zo hoog mogelijk te maken, rekening houdende met gemeentelijke taakstellingen.

\section{Literatuur}

Ager, A., \& Strang, A. (2008). Understanding integration: A conceptual framework. Journal of Refugee Studies, 21 (2): 166-191.

Andersson, L., \& Hammarstedt, M. (2015). Ethnic Enclaves, Networks and Self-Employment among Middle Eastern Immigrants in Sweden. International Migration, 53 (6): $27-40$.

Andersson, R., Musterd, S., \& Galster, G. (2019). Port-of-Entry Neighborhood and Its Effects on the Economic Success of Refugees in Sweden. International Migration Review, 53 (3): 671-705.

Bansak, K., Ferwerda, J., Hainmueller, J., Dillon, A., Hangartner, D., Lawrence, D., \& Weinstein, J. (2018). Improving refugee integration through data-driven algorithmic assignment. Science, 359: 325-329.

Bansak, K., Hainmueller, J., \& Hangartner, D. (2017). Europeans support a proportional allocation of asylum seekers. Nature Human Behaviour, 1 (7): 1-6.

Beaman, L. (2012). Social Networks and the Dynamics of Labour Market Outcomes: Evidence from Refugees Resettled in the U.S. Review of Economic Studies, 79: 128-161.

Boot, N., \& Driessen, Z. (2019). Dynamiek in de demografie van Syrische statushouders. In: E. Miltenburg, J. Dagevos \& W. Huijnk (red.), Opnieuw beginnen. Achtergronden van positieverschillen tussen Syrische statushouders. Den Haag: Sociaal en Cultureel Planbureau, 35-51.

COA (2020). Huisvesting van statushouders. www.coa.nl/nl/huisvesting-van-statushouders, geraadpleegd op 13 september 2020. 
Damm, A. (2009). Ethnic Enclaves and Immigrant Labor Market Outcomes: Quasi-Experimental Evidence. Journal of Labor Economics, 27 (2): 281-314.

Edin, P., Fredriksson, P., \& Åslund, O. (2003). Ethnic Enclaves and The Economic Success of Immigrants - Evidence from a Natural Experiment. The Quarterly Journal of Economics, 329-357.

Engbersen, G., Dagevos, J., Jennissen, R., Bakker, L., \& Leerkens, A. (2015). Geen tijd verliezen: Van opvang naar integratie van asielmigranten (WRR-Policy Brief 4). Den Haag: Wetenschappelijke Raad voor het Regeringsbeleid/Sociaal en Cultureel Planbureau/ Wetenschappelijk Onderzoek-en Documentatiecentrum.

Fasani, F., Frattini, T., \& Minale, L. (2018). (The Struggle for) Refugee Integration into the Labour Market: Evidence from Europe (IZA Discussion Paper 11333).

Gerritsen, S., Kattenberg, M., \& Vermeulen, W. (2018). Regionale plaatsing vergunninghouders en kans op werk. Den Haag: Centraal Planbureau.

Huisman, C. (2020). Syrische statushouders op weg in Nederland: De ontwikkeling van hun positie en leefsituatie. https://digitaal.scp.nl/syrische-statushouders-op-weg-innederland/demografie, geraadpleegd op 18 september 2020.

Huizinga, R. (2019). Maak plekken centraal in de hervestiging van Syrische statushouders. www.socialevraagstukken.nl/maak-plekken-centraal-in-de-hervestiging-van-syrischestatushouders/, geraadpleegd op 13 september 2020.

Jansen, J. (2006). Bepaalde huisvesting: een geschiedenis van opvang en huisvesting van immigranten in Nederland, 1945-1995 (Proefschrift). Leiden: Leiden University.

Kristiansen, M. (2020). Contacts with Benefits: How Social Networks Affect Benefit Receipt Dynamics in the Netherlands (Proefschrift Universiteit Utrecht).

Laan-Bouma-Doff, W. van der (2007). Involuntary Isolation: Ethnic Preferences and Residential Segregation. Journal of Urban Affairs, 29 (3): 289-309.

Liempt, I. van, \& Staring, R. (2020). Nederland papierenland. Syrische statushouders en hun ervaringen met participatiebeleid in Nederland. Den Haag: Sociaal en Cultureel Planbureau.

Martén, L., Hainmueller, J., \& Hangartner, D. (2019). Ethnic Networks Can Foster the Economic Integration of Refugees. Proceedings of the National Academy of Sciences, 116 (33): 16280-16285.

Musterd, S. (2003). Segregation and integration: A contested relationship. Journal of Ethnic and Migration Studies, 29 (4): 623-641.

Pinkster, F. (2009). Neighborhood-based networks, social resources, and labor market participation in two Dutch neighborhoods. Journal of Urban Affairs, 31 (2): 213-231.

Rijksoverheid (2017). Hoe verloopt het aanvragen van asiel?www.rijksoverheid.nl/ onderwerpen/asielbeleid/vraag-en-antwoord/procedure-asielzoeker, geraadpleegd op 13 september 2020.

Sinnema, L. (2020). Wel huizen, geen statushouders: Drentse en Groningse gemeenten halen taakstelling van 2019 niet. www.dvhn.nl/drenthe/Wel-huizen-geen-statushoudersDrentse-en-Groningse-gemeenten-halen-taakstelling-van-2019-niet-25333907.html, geraadpleegd op 13 september 2020.

Uslaner, E.M. (2012). Segregation and Mistrust: Diversity, Isolation, and Social Cohesion. Cambridge: Cambridge University Press.

VNG (2016). Factsheet integratie en participatie voor gemeenten. https://vng.nl/files/vng/ 20161213-factsheet-integratie-participatie-gemeenten.pdf, geraadpleegd op 13 september 2020.

Willen, S. (2019). Algoritme plaatst statushouder. www.binnenlandsbestuur.nl/digitaal/ nieuws/algoritme-plaatst-statushouder.9827385.lynkx, geraadpleegd 13 september 2020. 
Een ander perspectief op het spreidingsbeleid voor statushouders

Zhou, M., \& Portes, A. (1992). Chinatown: The Socioeconomic Potential of an Urban Enclave. Philadelphia: Temple University Press. 